\title{
An Analysis of the Artistic Photography of Digital Technology Creation
}

\author{
Bin Luo \\ School of Art and Design \\ Xi'an University of Technology \\ Xi'an, China
}

\begin{abstract}
The influence of painting on photography has always been accompanied by the development of photography. The digital technology is not only the subversion of traditional technologies and aesthetic concepts but also the inheritance and development of traditional photography. Due to the influence of digital technology, beginning of the invention of photography, the artistic photography was born with a new idea: combining the characteristics of digital photography and the expression of pictorial photography to further broaden the expression of photography, and also provide new ideas for the digital photography creation. At the same time, the photographic traditional techniques with painterly characteristics that were overlooked during the development of Chinese photography have also gained new development with the help of digital technology. The combination of modern technology and traditional crafts has become a useful attempt to explore new forms and directions of photography creation.
\end{abstract}

Keywords-artistic photography; painterly characteristics; traditional crafts

\section{INTRODUCTION}

Digital technology revolutionized photography in less than 40 years. Especially in the new century, in a short span of 10 years, the influence of digital technology on photography creation has had a direct impact on photography techniques, creative ideas, post-production methods, and art review methods.

Today, with the popularization of digital photography, many artists, scientists, thinkers, philosophers, and ordinary citizens with independent thinking and artistic creation skills are all involved in the creation of photography, so the concept of photography and its creative methods have been changed in various ways under the influence. However, if we want to produce original photographic works, we should first realize that the creation of photography still has relative limitations, and this limitation is pluralistic. We can understand the limitation from the following aspects: First, "function-oriented photography." Many photographers are pursuing the function that photography born with - recording "reality". This feature has been confirmed by the history of photography as misreading and perjury. In the digital age, when images produced by physical and chemical means were reproduced by photoelectric signals and could easily be modified by computers, "photography focusing on function" has become a self-discipline and industry standard in the field of photography. Second, "ideas -oriented photography." Many artists use photography as a means of creation, they combine photography with other expression forms to express their own artistic thoughts. This technique was widely circulated at the beginning of photography, but the artistic thoughts were embodied by painting at that time. Third, "digital-oriented photography", digital technology made the post-processing of photographs an indispensable means, which can correct the deficiencies of pre-photography and make the final photographs ever-changing, but the technology made some elements of traditional photography ignored or even abandoned by most people. Looking at the characteristics of current photography creation, for the "function-oriented photography", the involvement of digital technology does not change the nature of the image expression. "Ideas-oriented photography" actually exists in any categories of photography, it is only a matter of occupying a major position or a subordinate position. The concept expression exists in both traditional era and the digital era, and the involvement of digital technology makes the expression have more possibilities, which should be explored. The "digital-oriented photography" brings a lot of differences from traditional photography due to its technological innovation: changing the darkroom into the bright room, changing the flushing into printing, changing man-made into the mechanic, changing the chemical image into the physical image and changing the preexpected change to later correction. We should reflect on from all of these changes: digital technology and the concept of expression, digital technology and post-production, digital technology and traditional technology, should be developed together or turn over a new leaf? It is necessary for photographic creation in the digital age to research in-depth on this aspect.

The mother of photography is painting, and the painter's painting box is the original form of the camera [1]. The early photographers were mostly transformed by the painters. The new technology form photography directly refers to and imitates mature painting art in terms of expression, so that painting photography occupied an important position for quite a long time. During this period of time, the aesthetic perception of photography has always been influenced by that of painting. Artistic photography also occupies an important position in the entire history of photography. Before and after it, there surged several photography schools similar to the 
school of painting, such as genre painting and impressionism photography [2]. Nowadays, only 170-year-old photography has once again undergone tremendous changes due to technological innovation. The birth of digital technology makes the expression and form of photography enter a new field and introduces factors that need to be explored and unknown. Although digital technology has eliminated some elements of traditional photography, the nature of digital technology has led us to think about digital and traditions. At the same time, this technology provided more possibilities for the creation of photography. The recombination of digital photography and painting become a new opportunity for the development of photography art.

\section{NEW "ARTISTIC" PhOTOGRAPHY USING DigitAL TECHNOLOGY}

Artistic photography takes a place in the history of photography. With the development of painting, the photography schools also produced photographs similar to their "idea". The "meaning" of their works is based on people's understanding of "painting". The emergence of digital technology facilitates the layout of photography as painting, and also gives new meaning to "painting."

\section{A. Re-borrowing the Form of Traditional "Painting"}

Prior to the advent of digital technology, there were Chinese paintings produced by photography. In composite picture of the Chinese photographer Lang Jingshan, he produced Chinese photography-style photographs by late-stage collage synthesis of darkrooms, which is similar to the imitation of painting of Robinson at the beginning of photography. Among contemporary Chinese photographers, artists such as Yao Lu, Yang Yongliang, and Wang Qingsong, taking traditional form of Chinese painting as a reference, created outstanding works that reflect current social development by photography.

Means to make modern digital photography is similar to its predecessors in the traditional ink painting. It is usually a collage. This is an effective way to obtain perspectives on Chinese traditional paintings, but the difference is that it is generated by computer and constitutes a traditional and modern alternative theater space. It often conceives the overall poetry of the painting according to the aesthetics of Chinese landscape painting. However, what is ultimately conveyed is the new artistic sight that completely subverted the traditional aesthetics of Chinese painting. [3]

One of Yao's works, "China Landscape 1" series in "Fig. 1", refers to Chinese traditional landscape painting. The construction of buildings everywhere in a high-growth society brings to all the viewers an image of a mound covered with green nets for the purpose of "beautification", which precisely coincides with the image of "mountain" in Chinese traditional landscapes, and then decorated with other artistic elements such as pavilions, terraces and towers, constitutes a modern digital photography that resembles green landscape painting.

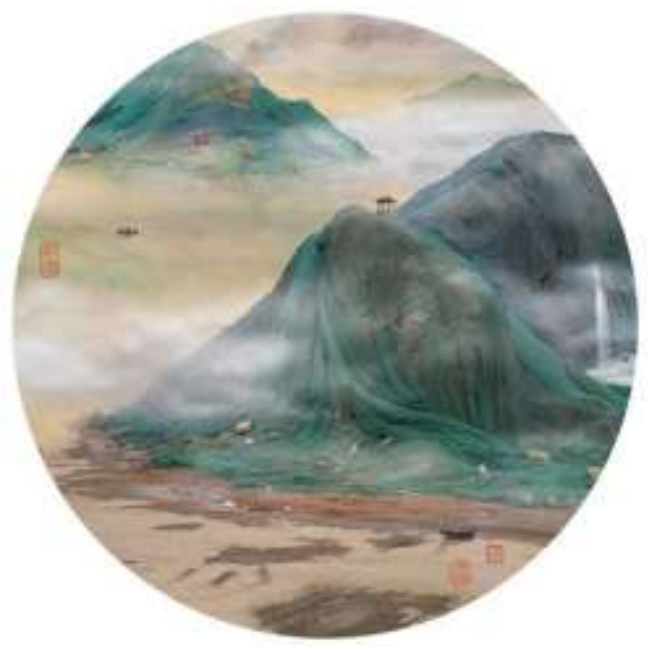

Fig. 1. China Landscape1, Yao Lu.

Comparing to the Chinese landscape paintings of the Song Dynasty with the "Spirit Mountain pavilion map" in "Fig. 2", the screen forms are exactly the same. The interpretation of the traditional green landscapes becomes an entry point, the production of clouds with digital synthesis and digital postproduction highlights the artistic conception, and the use of digital means makes the expression of ideas became a reality. It provides us with another dialogue between traditional aesthetics and photography. [4]

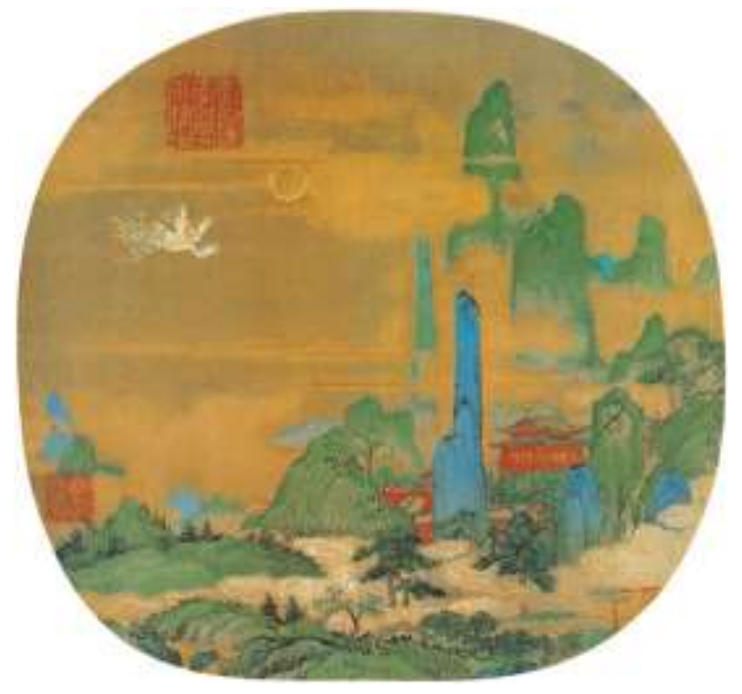

Fig. 2. Spirit Mountain pavilion Map, Song Anonymous.

If Yao's works still has the shadow of traditional collages and digital technology is not yet obvious, then the works "Illusion city landscape-XiaShan figure" of photographer Yang Yongliang applies the collage technique to the height that traditional collage cannot reach. It is also a form of borrowing traditional Chinese landscape painting. However, the role of digital technology makes the work more than merely a form of impact, and the high-density combination of digital images also brings visual shock to the photographic images. The processing of digital technology becomes the main means of photographic art creation. 


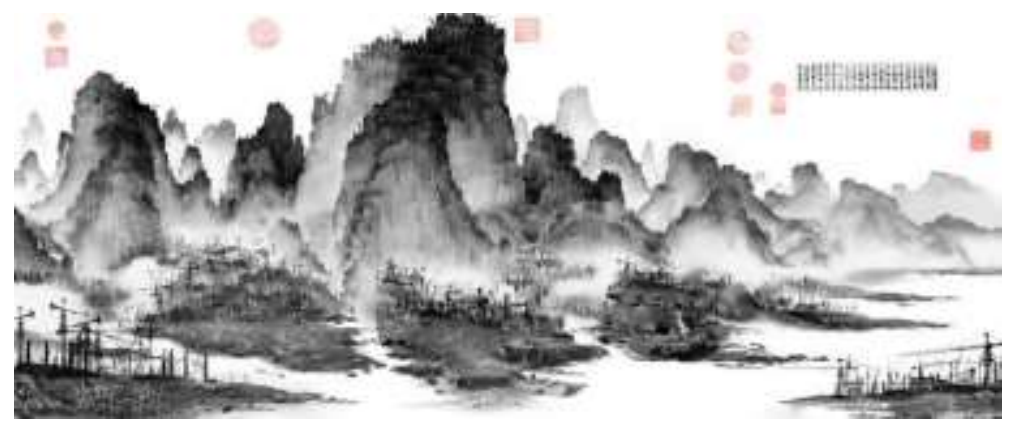

Fig. 3. Yang Yongliang. Illusion City Landscape- The Second Xiashan Figure.

Similarly, works used digital technology combined with traditional paintings includes "Thoughts the portrait of a lady" of Kuang Da, it is a borrowing of the famous painter Zhou Fang's "Thoughts the portrait of a lady". The picture exchanges by digital technology and traditional painting, makes pictures itself into ancient painting, which gives the

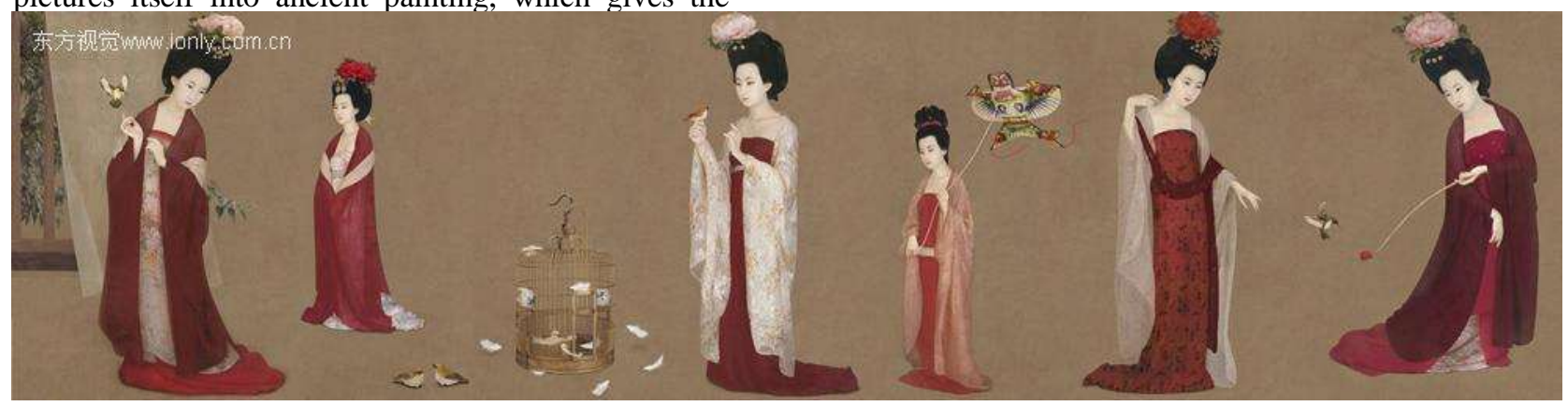

combination of photography and painting a new meaning. Digital technology expands the space for photographic expression. Meanwhile, it makes traditional art works of painting enter the contemporary artistic vision with new expression concepts in "Fig. 4".
Fig. 4. Thoughts the Portrait of A Lady, Kuang Da.

The borrowing of traditional paintings is not only reflected in domestic photographers, but also a group of outstanding abroad artists. So the borrowing works are international and cross-cultural.

"I start from not taking photos." "Painting is making images, and so is the photo. I think there is a connection between the two. It is a very broad and open space." The Canadian artist Jeff Wall started thinking about the relationship between photography and painting as well as creating works combined the two in 1976. [5] He actively took the most advanced digital image synthesis technology and got inspiration of compositions and themes from famous paintings of the world and produced a series of huge light bulb works with strong advertising colors. The works are photographs, and the appearance of paintings being clearly seen on these works is reprocesses of painting images, it is the photograph with a new meaning. It is some artificially constructed reality, a fictional plot that originates from the life but is highly refined. It finally presents the real problems of the society, attracting people's attention to reality and prompting people to think about the boundaries between photography and painting, the authenticity of photographic art, etc. [6] "Fig. 5" In addition, JEFF WALL's reference to painting is also multifaceted. He not only borrowed the appearance of paintings. "All along, the photos are viewed based on the size of the book or the album. However, I still think that photography and painting have some kind of blood relationship that not being discovered. Then I went to Europe and walked around to see a variety of video- media advertising light boxes on the street and paintings in the museum. I suddenly had an idea in my mind to do PPT, Maybe I could do works with some elements of Titian and Francisco José de Goya y Luciente "[7]

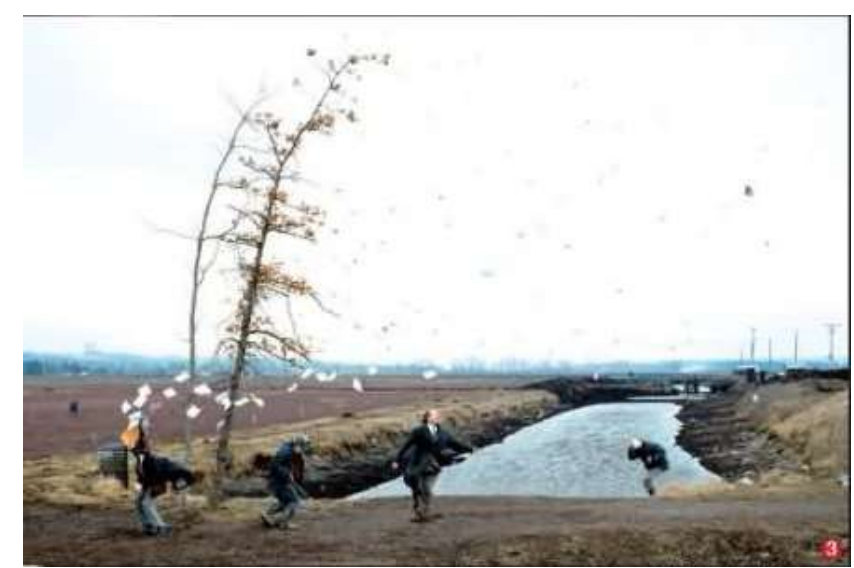

Fig. 5. Gust Jeff Wall.

The reference to painting is not only embodied in image language, JEFF WALL's reference to painting display is also a direction we need to explore on the combination of photography and painting. 


\section{B. The Production Process of Digital Photography Is More Pictorial}

"Painting" refers to visual forms outside of the subject matter, manual traces, and individualized emotional tastes, etc. drawing in two-dimensional plane paintings; "painting" gives humanity and life traces to works, creating an illusion of the presence of the creator. [8] Digital photographic technology eliminated the instantaneous consciousness of traditional photography to a certain extent. In the traditional concept of "photography", we will demand the so-called unity of time and space; [9] the concept of time is the key factor for photography to promote images. "Instantaneous" aesthetics is the unique characteristic of the photographic art. For a long time, the creation of photographic works has paid attention to the early period of shooting - that is, thinking before shooting and moments used for photography, this characteristic has even become the core of photography aesthetics, and most of the post-production process of photographic works have fallen into slavery of them. The timely review of digital photography technology and the convenience of image acquisition make photographic images appear more often in the form of "materials," and the aesthetic sacredness of shooting moments turns into post-production for "materials"- which is similar to the artificial traces of painting. Through the accumulation of certain time, the re-creation of visual forms makes this process with more nature of painting.

In addition, powerful computer software makes it a common practice for us to "paint" a photo into a new work. This characteristic is particularly evident in Yang Yongliang's works. In the later stages of the production, the "material" photographs of the layers are the same as texture stroke of the ink painting, and they eventually constitute traditional landscape paintings. Furthermore, the digital photography's flexible control of the screen, including the tone, the purity of the color, and the visual texture of the image, make the process of photographic creation closer to painting.

We can even completely abandon the shooting methods of photography and use computer software to "draw" "photos". Miao Xiaochen's works "Virtual Final Judgment" by 3DMAX software imitates Michelangelo's "Final Judgment" painting with virtual images. This is an experiment to express video by virtual images. He chose the works of the Renaissance masters to reinterpret, which in turn gave viewers a rethinking of digital photography and traditional painting. The creation of 3DMAX makes the original two-dimensional image a threedimensional image. The viewer can view the work from the individual's perspective, enabling the viewer to create a new experience. [10] This is an organic combination of "artistic painting" and pictorial painting in digital technology and a combination of new techniques in photography and painting.

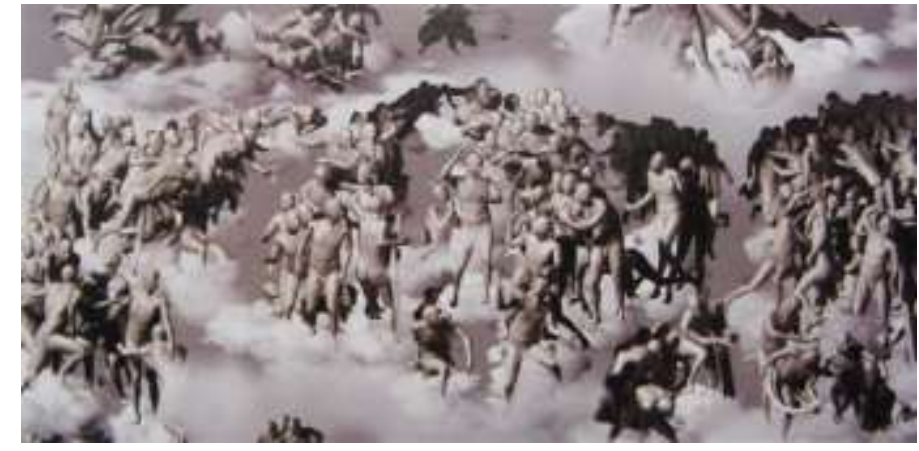

Fig. 6. Virtual Last Judgment Miao Xiao Chun.

\section{Digital TRADITIONAL PhOTOGRAPHY CRAFTSMANSHIP}

Most of the classical techniques of photography are inextricably linked with painting in their craft, and they have more similarities: obvious handmade traces - hand-painted emulsion, handmade paper, strong personal interest, similar painting techniques and the effects of similar paintings, which enable the photographic art to be further developed with the aid of digital techniques in "Fig. 7".

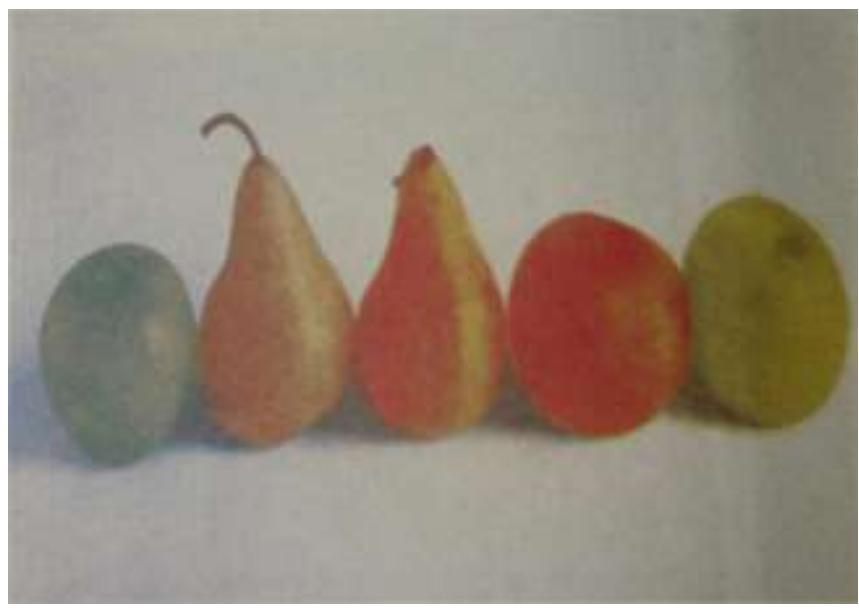

Fig. 7. All Kinds of Fruits and No. 6 Works, Mary Pat McNally.

\section{A. Traditional Photography Craftsmanship Is Reborn by Digital Technology}

Traditional photography craftsmanship is the form of photographic art that has gradually been marginalized with the development of photography technology. Marginalization is due to the backwardness of technology and cannot meet commercial needs, but it does not mean that it is untimely in terms of artistic expression. In our country, this form of photography suffers from technological elimination almost without entering the halls of the photographic arts: the scarcity of large-scale films and the demise of traditional large-scale camera production cause traditional crafts face the exhaustion of resources. And the scarcity of materials will undoubtedly constrain the development of traditional craft from the root. At the same time, digital technology brings new development conditions for traditional crafts. The production of digital negatives makes the transfer process become the main process 
in traditional craft, such as iron-silver printing and platinum/palladium printing, blue drying process, etc. They not only get new solutions, but even get further development.

"Previously, channel separation by traditional chemistry methods took quite a long time. Now with the help of Photoshop or Illustrator, with just a few mouse clicks, the acetate film can be printed at a very high resolution. The tedious work was completed in a matter of minutes. In addition, the ever-changing printing technology makes the digital copy of the film a reality, and its performance parameters even surpass traditional negatives."[11]

Needless to say, the digital printing of negative film makes the printing process in the classical arts new development, and the digitalization is not only reflected in the digital negative film printing. The digitization of the shooting and the digitization of the image post-processing also provide more creative possibilities for the traditional printing process. The digitization of Shooting- digitizing image processing outputting digital negatives allows us to produce print works that exceed the size of traditional film shots. In addition, the digital processing of images further expands the performance of traditional photographic techniques, "negative films separate in the CMYK of Photoshop. After the traditional transfer process, we finally get a photo with vivid colors. The success also told me the importance of using digital technology in the traditional process in "Fig. 8". [12].

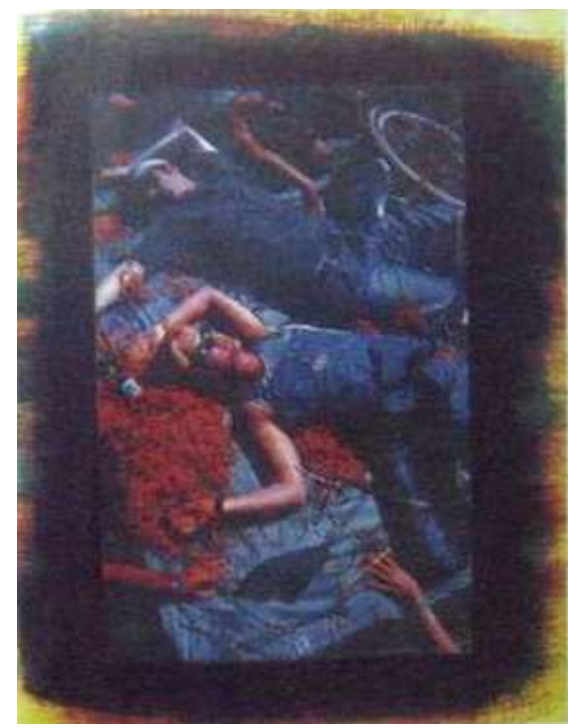

Fig. 8. E Channel Separation Digital Negative Making Four-Color Gum Bichromate Photos, John Quackenbos.

Digital color separation plays a crucial role in this work. However, this is only part of the application of digital technology. The application in the digital processing of images and the innovation of later stage still needs to be continuously explored in practice. The process-like effects of classical photography painting and the uncertainty of manual operation will show its infinite charm in practice.

\section{CONCLUSION}

The creation of photography under the digital technology environment is diversified. The new technology brings new opportunities for photography creation. It is necessary to make use of new technologies to constantly innovate and absorb nourishment from the tradition. It is necessary to refer performance form and combine with other elements of the painting language, such as the material characteristics of paintings, the display of paintings, and so on. Only broadening ideas, learning from people's merits, and being diversify can gain more in photographic art creation.

\section{REFERENCES}

[1] Zhang Qian. Photography and painting. Pixel [J]NO.3 张谦.摄影与绘 画.像素[J]NO.3

[2] Li Wenfang. History of Photography [M]. Heilongjiang: Heilongjiang people's publishing house，2004.1 李文方.摄影史[M]. 黑龙江：黑 龙江人民出版社, 2004.1

[3] Gu Zheng. The "drama" and "field" in Shanghai Watching [J] Photograph 2009(3) 顾铮.上海观看中的 “剧”与 “场” [J]. 照相 2009(3)

[4] Wang Chuan. The sky here [M]. Zhejiang: Zhejiang photography press.2010.1 王川.这儿的天空[M]. 浙江: 浙江摄影出版社.2010.1

[5] admin. Interview with Jeffwall http://xno1qx8e8wscpk.com/photographic-theory/ admin. 杰夫瓦尔访谈 http://xn--o1qx8e8wscpk.com/photographic-theory/

[6] Gu Zheng. Photo world[M].Shanghai: Shanghai pictorial press.2002 顾铮.世界摄影[M].上海: 上海画报出版社.2002

[7] Interview with Jeffwall. http:// Ancient imaging.com/photographictheory 杰夫 • 沃尔访谈 http://古法成像.com/photographic-theory

[8] Tony The madness of 195 years. Preface of Review of the exhibition of contemporary painting http://www.longyibang.com/showscn.htm 托尼 195 年的迷狂审视当代绘画 展览前言 http://www.longyibang.com/showscn.htm

[9] Wu Hong Artists and photographers, who are "deceptive"? http://www.tiantaiquan.com/index.php?/text/ 吴鸿 艺术家与摄影师, 谁在 “骗人”? http://www.tiantaiquan.com/index.php?/text/

[10] Fan Xiaoying. The fusion of photography and painting [D].Zhejiang: vientiane, 2009.12 范晓颖.摄影与绘画的融合 [D].浙江: 万象论文 集, 2009.12

[11] Written by Christopher James, translated by Lu Jiajia. The book of alternative photographic process [M]. Shanghai: Shanghai fine arts publishing house..2006.6 p66-70 克里斯多佛 - 詹姆士著, 陆佳加译. 美国摄影图片制作工艺专业教程 [M]. 上海: 上海美术出版 社.2006.6 p66-70

[12] Written by Christopher James, translated by Lu Jiajia. The book of alternative photographic process $[\mathrm{M}]$. Shanghai: Shanghai fine arts publishing house..2006.6 p66-70 克里斯多佛 - 詹姆士著, 陆佳加译. 美国摄影图片制作工艺专业教程 $[\mathrm{M}]$. 上海: 上海美术出版 社.2006.6 p66-70 